


\section{Distanciamiento ilustrado en las argumentaciones deconstructoras de Rousseau}

\section{Rousseau's Dissent and Deconstruction of Enlightened Rationality}

Francisco Javier Higuero Wayne State University

Resumen

En conformidad con lo explicado por Jean-Jacques Rousseau a lo largo de su producción filosófica, el estado ideal de la naturaleza no sólo se define como anterior a categorizaciones lingüísticas, sino que, hasta cierto punto, ha sido romantizado por diversos críticos, abocados a presentar las ideas de dicho pensador como marcadamente alejadas de la premisas y propuestas esgrimidas por el movimiento cultural de la Ilustración. Tal estado originario de la naturaleza se presta a ser considerado como pacífico, harmónico, vacío de envidia y prelingüístico o silencioso. En semejantes circunstancias, el habitante de tal entorno natural se aproximaba al mundo directamente y sin las fisuras producidas por elucubraciones culturales, provenientes de dictámenes civilizatorios. Sin embargo, la teoría de la voluntad general, defendida por Rousseau en El contrato social, desarrolla estrategias argumentativas dirigidas a superar el aislacionismo congénito al habitante del estado de la naturaleza, intentando deconstruir la dicotomía binaria que enfrentaba a la abstracta racionalidad ilustrada con la inmediatez de la experiencia primigenia. 
Palabras clave: contrato social, deconstrucción, dicotomía binaria, discurso, felicidad, Ilustración.

\begin{abstract}
The ideal state of nature, as explained in Jean-Jacques Rousseau's philosophical production, is not only defined as non-linguistic, but also has been, to certain extent, romanticized by many critics who present the ideas of this thinker as distant from the premises and proposals that the cultural movement that the Enlightenment defended. Such an primary state of nature was considered to be blissful, peaceful, harmonious, void of envy or jealously and prelinguistic or silent. Related to this circumstance, man's natural view of the world was immediate and whole, unfractured by language and articulated words. However, when Rousseau presented in The Social Contract his theory of the General Will, he developed argumentative strategies directed to overcome the isolationist connotations of the state of nature and to deconstruct the binary dichotomy that exists between abstract rationality and unmediated experience.
\end{abstract}

Keywords: Social contract, Deconstruction, Binary dichotomy, Discourse, Enlightenment, Happiness.

Si se tratara de prestar la debida atención a las provocadoras proción filosófica de Jean-Jacques Rousseau, quizás convendría evitar caer en la tentación de caracterizar a este pensador con el calificativo de innovador, sobre todo en lo que se refiere a la elección de muchos, e incluso de la mayoría, de los temas por él abordados. Han sido tanto Manuel Casás Fernández en Voltaire Criminalista, como también Ińaki Iriarte en Una cruel antifrasis, quienes tienen a bien advertir que las creencias esgrimidas por Rousseau acerca de un orden natural, expresión al vez de la voluntad divina, finalista 
e inmutable, no difieren en lo esencial de las de Voltaire. ${ }^{1}$ A todo esto conviene agregar que la visión de la física ostentada por Rousseau mantiene básicamente el punto de vista de René Descartes y algo parecido acaece en la cuestión del libre albedrío. Sin embargo, no resultaría redundante afirmar que si Rousseau no se presenta novedoso en sus temas ni tampoco en algunas líneas maestras de sus propuestas, en otro sentido su filosofía no deja de poseer una aire atípico, puesto que desde ella se lleva a cabo una crítica deconstructora, tan apasionada como fascinante, de la cultura, y un ataque frontal contra lo ostentado públicamente por una sociedad basada en la vanidad y el disimulo. En conformidad con lo advertido por James Delaney en Rousseau and the Ethics of Virtue, se precisa adelantar, desde un primer momento y a este respecto, que Rousseau contrapone las virtudes del estado de naturaleza, reivindicadas con insistencia manifiesta por dicho pensador, a los vicios inherentes a la sociedad corrupta. Las páginas que siguen aspiran a indagar en los razonamientos exteriorizados por las argumentaciones esparcidas a lo largo de los escritos ensayísticos de Rousseau, para así contribuir a esclarecer las conclusiones sacadas y los correspondientes corolarios especulativos, inconmensurables, en gran medida, respecto a la cultura ilustrada, predominante en el Siglo de las Luces.

\section{Del amor de sí al sentimiento de piedad}

Según se desprende de lo explicado, con reiteración, por María Villaverde en Rousseau y el pensamiento de las luces, al contraponer

${ }^{1}$ La coincidencia de los planteamientos argumentativos de Voltaire y Rousseau no resulta ser total ni absoluta. De hecho, en contra de lo insinuado por este pensador en Discurso sobre las ciencias y las artes, Voltaire defendía, con indisimulada contundencia, el progreso social, llegando a criticar directa y explícitamente muchas de las propuestas de Rousseau. 
Rousseau el estado de naturaleza al de sociedad, afirma que en aquél no existe el amor propio, sino sólo el amor de sí. La diferencia cualitativa más notable entre estos dos amores es que el primero exige el reconocimiento de los otros hacia uno mismo, llegando a manipularlos y someterlos, del modo que fuere preciso, mientras que el amor de sí conduce simplemente a la autoconservación y no se mide respecto a la existencia de otros seres semejantes. Como parte de la autoconservación habría que referirse al afán por perdurar, no entendido éste como una competición con otros seres humanos. De hecho, el amor de sí implicará un encierre tan radical en uno mismo, que semejante sujeto ni siquiera llegaría a considerar a los demás, sea para amarlos u odiarlos. Conviene tener en cuenta que en el Discurso sobre el origen de las ciencias y las artes, Rousseau es consciente de las críticas en contra del amor propio que había prodigado Blaise Pascal en Pensées. Pero, por otro lado, la diferencia que esgrime Rousseau entre el amor propio y el amor de sí le permitirá aglutinar una buena porción de los argumentos de quienes, como Voltaire, llevaban a cabo una apología del sentimiento de autoconservación, además de aquellos, entre los que se incluiría Montaigne, propensos a postular, con cierta insistencia, el retorno a uno mismo como garantía de la felicidad. ${ }^{2}$ Ahora bien, se precisa reiterar una y otra vez que, en modo alguno, las propuestas ilustradas de Voltaire coinciden, por completo, con las disquisiciones naturalistas de Rousseau, y es precisamente tal distanciamiento conceptual, lo connotado semánticamente por la cruel antífrasis a que se refiere el título del mencionado escrito ensayístico de Iriarte López.

${ }^{2}$ En La Ilustración francesa, Arsenio Ginzo no sólo se refiere a las argumentaciones de Los ensayos de Montaigne, que pudieran coincidir con los planteamientos de Rousseau, sino también a las semejanzas y diferencias entre las respectivas propuestas de este pensador y las de Voltaire. 
Una lectura atenta de lo tratado por Rousseau en Discurso sobre el origen y los fundamentos de la desigualdad entre los hombres, contribuye a poner de manifiesto que el amor propio, sumamente criticado una y otra vez, no pasa de ser un sentimiento relativo, ficticio, artificioso, nacido de la sociedad. Tal amor cifra todo su afán en conseguir crear en los demás una imagen de superioridad de uno mismo y surge, por consiguiente, cuando se deja de mirar al yo y se comienza a mirar fuera. De hecho, se afirma en Una cruel antifrasis, que, según Rousseau, el hombre, al centrar todos sus esfuerzos en la imagen proyectada por él mismo, además de olvidarse de sí, hace del prójimo una pantalla de su vanidad. Dicho de otra forma, en tales tesituras, alguien solamente ve, en los demás miembros de su especie, instrumentos con los que confirmar los ensueños del amor propio. En conformidad con lo ya advertido, para Rousseau, el amor propio es un producto de la sociedad y el origen de enfrentamientos innecesarios, pues su contenido consiste en medirse con el prójimo, mientras que el amor de sí distinguiría al ser solitario y autosuficiente. En contraposición al carácter tranquilo y apacible del amor de sí, el amor propio se distinguiría por su condición violenta. A todo esto conviene agregar que, en el Emilio de Rousseau, se reitera que el amor propio genera pasiones artificiales, rencorosas e irascibles, incapaces de ser totalmente satisfechas, al tiempo que continúan mostrando una imposibilidad congénita para conseguir obtener una calma pacífica. Ahora bien, parece que este pensador no rechaza, por principio, todas las pasiones, pronunciándose a favor de las que se relacionan con la autoconservación, buscada en el estado de la naturaleza. Son únicamente las pasiones artificiales, fomentadas por el amor propio, procedentes a su vez, de las comparaciones establecidas entre determinados individuos, las que se convierten en objeto de crítica, al expresarse Rousseau de la siguiente forma en el Emilio: 
El amor de sí, que sólo nos afecta a nosotros, se contenta cuando nuestras verdaderas necesidades son satisfechas; pero el amor propio, que se compara, nunca está contento y no podría estarlo, porque ese sentimiento, al preferirnos a los demás, exige también que los demás nos prefieran a sí mismos, lo cual es imposible. Así es que las pasiones suaves y afectuosas nacen del amor de sí, como las pasiones rencorosas e irascibles nacen del amor propio (Rousseau, 1990: 315).

De acuerdo con lo ya adelantado, se afirma en el Emilio, que el amor propio y el amor de sí resultan ser dos conceptos muy diferentes. Este último procede de un sentimiento natural que consiste principalmente en la autoconservación y no en el establecimiento de comparaciones entre individuos concretos. Por consiguiente, cada cual sería el espectador de sí mismo y la única referencia adoptada. Todo esto implica un encierro tan radical, en sí mismo, que dicho sujeto ni siquiera llegaría a considerar a los demás, sea para amarlos u odiarlos. ${ }^{3}$ Como parte de semejante aislamiento, constatado por Rousseau, se incluye el hecho de que el hombre natural parece desconocer la intención tanto del pasado, como del futuro, viviendo sólo en el presente, pues no recuerda el ayer ni prevé el porvenir. Su objetivo exclusivo es la autoconservación y sus primeros cuidados son los que se debe a sí mismo. Sin embargo, no resulta superfluo insistir en el hecho de que dicha actitud del hombre natural no llega a materializarse en un ensimismamiento estéril, como consecuencia del cual no sería posible establecer ninguna transacción relacional de carácter intersubjetivo. De hecho, Rousseau abre la puerta a consideraciones igualitarias, al tratar alguien con su prójimo, merced al sentimiento natural de piedad. Tal actitud contrasta abiertamente con el posicionamiento

${ }^{3}$ El encerramiento en uno mismo, esgrimido en el Emilio, tal vez sea comparable a lo razonado por la filosofía idealista de Georg Wilhelm Friedrich Hegel, expuesta en algunos pasajes de Fenomenología del Espiritu. 
adoptado por Thomas Hobbes en Leviatán, cuando describe a los hombres que viven en estado de naturaleza, como participando en una continua y despiadada guerra. Frente a dicha agresividad, Rousseau afirma que el hombre natural siente un rechazo innato a ver sufrir a los semejantes. Lo esgrimido por dicho pensador en El contrato social coincide, a este respecto, con lo especulado por David Hume en Tratado de la naturaleza humana, al afirmar que el sentimiento de piedad no sólo es anterior incluso a reflexión conceptualizadora alguna, sino que posee también una fortaleza superior a cualquier depravación pasional, imposibilitada, de por sí, a eliminarlo definitivamente. Se pudiera especular, sin duda alguna, sobre las connotaciones semánticas proyectadas por la primacía concedida tanto por Hume como por Rousseau, al sentimiento de piedad, advirtiendo que éste precede al amor propio y que, por lo mismo, no coincide con algunas actitudes presuntamente compasivas, susceptibles a ser consideradas como derivadas de intereses protegidos o buscados. ${ }^{4} \mathrm{Si}$ se prestara la debida atención a lo argumentado por Juan Manuel Medrano en El reino celestial del cambio y José Manuel Romero Cuevas en ¿Con Nietzsche contra Nietzsche?, convendría puntualizar que Rousseau se separa del sentimiento de compasión, que le parece insuficiente, debido a motivos distintos de los aportados por Friedrich Nietzsche en La genealogía de la moral. Este filósofo rechazaba la compasión, ya que contribuía a incrementar el dolor existente. Tal y como lo ha puesto de relieve Robert Solomon en Living with Nietzsche, quien sufra con aquel individuo que experimenta dolor, contribuye a incrementar el sufrimiento existente, pues, como consecuencia de dicho posicionamiento, no sólo padece el sujeto que inicialmente se veía afligido por el mencionado dolor, sino que también llega a sufrir aquel que

${ }^{4}$ El desenmascaramiento de lo entendido en lenguaje común como compasión parece prestarse a ser objeto de las críticas fenomenológicas expuestas por Aurelio Arteta en La compasión, y La virtud en la mirada. 
siente compasión hacia el otro. En relación con este asunto, las argumentaciones de Rousseau son diferentes respecto a las de Nietzsche. El rechazo de la compasión evidenciado por aquel pensador se debe a que el individuo que se compadece adquiere una actitud de superioridad existencial en relación con el compadecido, mientras que el sentimiento de piedad coloca a ambos sujetos en igualdad de condiciones. En última instancia, tal sentimiento no nace como un cálculo egoísta, sino que viene a ser el resultado de una conmiseración espontánea. De hecho, la piedad debería concebirse, dentro de las argumentaciones llevadas a cabo por Rousseau, como constituyendo una modulación directa del amor de sí, al que, en todo caso, modera, evitando la producción del dańo ocasionado intencionadamente sobre el prójimo. ${ }^{5}$ Para decirlo de modo algo diferente, en el estado natural el sentimiento de piedad ocuparía el lugar que a las leyes atribuye Platón en la República, dentro de una sociedad ya formada y nunca exenta de las amenazas ocasionadas por la corrupción desvirtuadora, rechazada reiteradamente, una y otra vez, por Rousseau. No obstante, se precisa puntualizar que las argumentaciones de dicho pensador inducen a pensar que su concepción del sentimiento la piedad acaso no se halle muy alejada de lo que en Ética a Nicómaco y The Politics Aristóteles entiende por virtud, siendo la generosidad, la clemencia e incluso hasta la amistad, otras tantas derivaciones suyas.

\section{Amor propio y depravación corrupta}

De acuerdo con los razonamientos de Rousseau, pudiera parecer que, en pura lógica, la piedad sería un tipo de sentimiento que

${ }^{5}$ En De la tolerancia, Carlos Thiebaut explica lo connotado semánticamente por el concepto de daño y lo contrapone al del mal. Por daño se entiende una barbarie que hubiera podido ser evitada, mientras que el advenimiento del mal se encuentra más allá de los designios y libertades humanas. 
irrumpe sólo cuando se ha producido algún contacto o transacción relacional entre los hombres. Ahora bien, esto no equivale necesariamente a atribuirle a la piedad un origen social, pues cuando el buen salvaje siente lástima ante el dolor ajeno lo que hace es ponerse en lugar del paciente, imaginando que es él quien sufre. Por este motivo, no resulta superfluo afirmar que el amor de sí es la fuente de piedad. Fuera de ese sentimiento, el hombre natural viviría al margen de las pasiones o, dicho más exactamente, sólo experimentaría las que se derivan de necesidades primigenias apremiantes. Tal hombre no siente envidia, ni celos ni codicia ni odio ni ambición ni orgullo. Sin embargo, esto no ocurre porque busque la impasibilidad total o el dominio estoico sobre sí mismo, sino como consecuencia lógica de su propia autorreclusión. Puesto que ni siquiera llega a compararse con los demás y debido a que vive todo él en su propia interioridad, no puede desarrollar sentimientos viciosos superiores al relacionarse con los otros, ni llega a establecer todo tipo de paralelismos y contrastes. Semejantes pasiones vendrían a convertirse en un sobreañadido procedente de determinadas circunstancias sociales impuestas. Consecuentemente, afirma Rousseau en El contrato social que el hombre es bueno por naturaleza. Esa bondad originaria no deja de ser sino un efecto lógico del amor de sí y del aislamiento que conlleva. Así pues, como consecuencia del hecho de que el hombre natural no depende de nadie y vive encerrado en sí mismo, las únicas clases de transacciones relacionales capaz de establecer con sus semejantes habrían de basarse en la piedad, consistente ésta en ponerse en el lugar del otro cuando sufre. A todo esto convendría ańadir que es precisamente la ausencia de vínculos la que garantiza la independencia y, por lo tanto, el predominio del correspondiente carácter bondadoso, origen del sentimiento de piedad, que se materializa en la felicidad experimentada por el hombre primitivo, quien desconocía el hambre perpetua e insaciable que caracteriza a sus 
congéneres civilizados, pudiendo muy bien llegar a satisfacer apaciblemente sus necesidades que eran pocas y realmente asequibles. El mencionado contraste entre la felicidad del hombre natural y la depravación corrupta en la que se instalan entornos sociales civilizatorios es descrito y explicado de la siguiente forma por el discurso ensayístico de Una cruel antifrasis:

Las necesidades naturales dejan paso a las necesidades artificiales, de índole caprichosa, creadas por la imaginación y la razón y que estriban en la satisfacción del amor propio. A partir de entonces se tratará de ser más que los demás, sea más rico, más bello, más sabio, libertino o poderoso. Desde el punto de vista estrictamente biológico no es en absoluto necesario colmar tales necesidades, pero las pasiones que se derivan de ellas se exacerban, hasta el extremo de que el hombre civilizado hará cualquier cosa por calmarlas. Sin embargo, y en la medida en que esas pasiones se asientan en la imposible pretensión del amor propio de ser más estimado por los demás que lo que se aprecian a sí mismos, todo intento de saciarlas será vano (Iriarte López, 2007: 158).

Repárese en que la crítica frontal contra el ejercicio de la razón, relacionado con la sociedad rechazada por Rousseau, incompatibiliza las argumentaciones de tal pensador con las propuestas ilustradas, diseminadas desde diversas focalizaciones perspectivistas a lo largo del Siglo de las Luces, deconstruyéndolas consecuentemente. Por otro lado, tal rechazo no contribuye a acercar las disquisiciones de Rousseau a planteamientos netamente románticos, ya que los excesos artificiales de la imaginación se convierten también en objeto de crítica implacable. Expresado de otro modo, las argumentaciones discursivas de dicho pensador, deconstruyen la dicotomía binaria ejemplificada en la presunta oposición entre las tesis ilustradas y las persuasiones románticas, no estando de acuerdo completamente con los planteamientos esgrimidos por ninguno 
de ambos movimientos culturales. ${ }^{6}$ Se precisa no olvidar, a este respecto, que los abusos procedentes de un ejercicio irrefrenable de la imaginación no proliferan sólo al margen de las disquisiciones ilustradas, sino sobre todo, al multiplicar la sociedad las necesidades que van surgiendo por doquier, como efecto indiscutible de la firme instalación del amor propio, relacionado frecuentemente con un fingimiento ocultador y hasta engañoso. Debido a dicha actitud promovida por la misma sociedad, el hombre natural no halla acomodo en ella. Su amor de sí choca frontalmente con el amor propio imperante en la sociedad e inevitablemente dicho hombre natural devendrá un extraño, un extranjero, una figura odiada, temida y ridiculizada al mismo tiempo. Su sinceridad, piedad y benevolencia le llevarían a convertirse en objeto de engaño, causando, a su vez, una conmoción real entre los que sólo saben ocultarse y aparentar. Debido a la desconfianza que le suscitan las apariencias, Rousseau recela de expresiones superficiales, buscando el significado profundo de las mismas, al tiempo que no deja de sospechar, en general, tanto de la elocuencia, como de muchos otros recursos retóricos. Tal pensador rechaza explícita y manifiestamente los excesos, procedentes de la perversión del lenguaje que se han ido produciendo desde la antigüedad grecolatina. En consecuencia, el antagonismo de Rousseau hacia la utilización de la elocuencia y la retórica se remonta casi hasta los mismos orígenes del pensamiento occidental. Es en el Emilio, el lugar donde más abiertamente se plantean las argumentaciones de Rousseau acerca de esas estrategias lingüísticas, presentándolas siempre con un marcado acento negativo. Para dicho pensador, la retórica consiste

${ }^{6}$ Tal y como ha explicado J. Claude Evans en Strategies of Deconstruction, si se aceptaran las estrategias deconstructoras explicadas por Jacques Derrida en De la gramatología, La diseminación, Posiciones y La escritura y la diferencia, cabría admitir la inaceptabilidad de cualquier aproximación crítica basada en una serie de dicotomías binarias jerarquizadas, sean de la naturaleza que fueren. 
en un hablar interesado que toma a los presuntos oyentes como simples medios, y cuya finalidad se materializa en seducir, escondiendo las verdaderas intenciones. Expresado de otra forma, la elocuencia compartida tanto por las tesis ilustradas como por diversas modalidades románticas convierten al lenguaje en un arma para la mentira, la vanidad y el orgullo, siendo además el sustento de una sociedad que discurre entre la hipocresía, el engaño y el afán de destacar a toda costa. ${ }^{7}$ En contraposición a semejantes excesos retóricos, Rousseau defenderá la claridad, la sencillez, la espontaneidad enérgica, la sinceridad, la concisión, la brevedad y hasta el silencio. El lenguaje que no se atuviera a esa cualidades le merece a Rousseau el mismo desprecio exhibido ya con anterioridad tanto por Montaigne, como también por Descartes y hasta por Leibniz, quien, en Nuevos ensayos sobre el entendimiento humano, se había pronunciado a favor de una nítida precisión, clara y distinta, que favoreciese el ejercicio de sus especulaciones metafísicas. ${ }^{8}$

\section{Desmantelamiento subversivo emanado de la voluntad general}

Al considerar discursivamente el estado de la naturaleza, Rousseau llegó a prestar atención a lo entendido por él como el presunto primer lenguaje, calificado de universal, enérgico y necesario, el cual vendría a ser algo así como un grito, quizás no muy diferente

${ }^{7}$ La propuesta pedagógica del Emilio se encamina a alejarse, con contundencia, de cualquier conocimiento tendente a facilitar un uso instrumental y hasta estratégico del habla.

${ }^{8}$ El interés colocado en una utilización apropiada del lenguaje, en el caso de Rousseau, no se debía a fomentar la eficacia raciocinante de las disquisiciones filosóficas propugnadas por Descartes y también por Leibniz, sino a reivindicaciones éticas, contrarias a lo ostentado por quien deseara mostrar su superioridad sobre todos aquellos contra los cuales compite ferozmente, en una sociedad alejada ya del estado primigenio y benevolente de la naturaleza. 
al flujo inarticulado a que se referían los jansenistas de Port-Royal cuando analizaban la interjección, declarándola el tipo más natural de expresividad. ${ }^{9}$ Ahora bien, en El discurso sobre el origen de la desigualdad, Rousseau parece suponer que el estado de la naturaleza resulta ser tan tranquilo que en él ni siquiera se sufren habitualmente dolores o amenazas propensas a provocar gritos instintivos. Por eso, a juicio de dicho pensador, el primer lenguaje tendría muy poco que ver con las pasiones que todavía no habían hecho acto de presencia y, por consiguiente, no habían sido afectadas por los excesos desvirtuadores promovidos por la elocuencia y la retórica, En lugar de caer en dichas desviaciones a las que la sociedad somete al lenguaje primigenio, afirma Rousseau que tanto las expresiones de los gestos, como las de la voz, son naturales, pero las de aquél resultan más sencillas y menos sujetas a convenciones. En Essai sur l'origine des langues, Rousseau advierte explícitamente que la historia de los diversos modos de comunicación vendría a materializarse en algo así como una suerte de pérdida, análoga a la decadencia de la bondad natural por causa de la sociedad. Consecuentemente, las primeras formas de comunicación son siempre más fidedignas, directas y expresivas que las ulteriores y la razón de ello estriba en que aquellas en lugar de decir tendían a mostrar, algo posible porque el hombre, inserto en el estado de la naturaleza, no analizaba, sino que simplemente percibía. La primacía otorgada por Rousseau hacia expresiones que tienden a señalar algo, en contraposición a lo promovido en análisis lingüísticos posteriores, sean de una modalidad u otra, aproximaría su pensamiento más a las teorías pictóricas explicadas por Ludwig Wittgenstein en el Tractatus Logico-Philo-

\footnotetext{
9 Según ha advertido Alexander Sedgwick en Jansenism in Seventeenth-Century France, los miembros de Port-Royal sentían un notorio despego hacia la sociedad, en donde dominaba, según ellos, la vanidad, el orgullo, la pedantería, la hipocresía, manifestaciones todas ellas del amplio dominio ejercido por el amor propio.
} 
sophicus que a las posteriores elucubraciones pragmatistas puestas de relieve a lo largo del discurso argumentativo de Philosophical Investigations..$^{10}$ No obstante, conviene puntualizar que la línea argumental de Rousseau se presta a hacer resaltar que el lenguaje más enérgico es aquél en donde el signo lo ha dicho todo, incluso antes de comenzar a hablar. Es muy posible que Wittgenstein no necesariamente esté de acuerdo con el valor semántico concedido por Rousseau a determinadas expresiones inarticuladas, difícilmente propensas a ser calificadas como lingüísticas. No debería olvidarse, a este respecto, que Rousseau llega a defender el hecho de que los hombres embargados por el amor de sí no requieren más lenguaje que el proveniente de los gestos, abocados a expresar las frugales necesidades del yo autónomo, sin fragmentarlas directamente y sin dar cabida a la comparación ni tampoco a las pasiones artificiales, pero posibilitando siempre el sentimiento de la piedad. Aquellas necesidades provocarían gestos, mientras que las pasiones llegan a crear el lenguaje articulado, contribuyendo verosímilmente al predominio ineludible de la perversa lógica imperante en la sociedad

${ }^{10}$ Para una mayor precisión de lo que expone Wittgenstein en la primera parte de sus raciocinios, convendría consultar estudios de imprescindible valor crítico, tal y como son los de Max Black en A Companion to Wittgenstein's "Tractatus", María Cerezo en Lenguaje y Lógica en el "Tractatus" de Wittgenstein. Crítica interna y problemas de interpretación, The Possibility of Language. Internal Tension in Wittgenstein's "Tractatus" y "El pensamiento y la triple dimensión de la figura en el Tractatus," Hans-Johann Glock en A Wittgenstein Dictionary, Alfred Nordman en Wittgenstein's "Tractatus." An Introduction y Anthony Rudd en Expressing the World. Skepticism, Wittgenstein, and Heidegger, entre otros muchos que pudieran ser tenidos en cuenta a tal respecto. No obstante, convendría puntualizar que, de dichas aproximaciones al pensamiento de Wittgenstein, se deriva que la teoría pictórica de los lexemas y proposiciones, explicada en el Tractatus Logico-Philosophicus, no es la única vertiente disquisitoria en él esgrimida, ya que los pertinentes raciocinios expuestos a lo largo de tal escrito filosófico sientan también las bases precisas y rigurosas, aunque sólo fueran de carácter germinal, para llevar a cabo ulteriores tratamientos lógicos. 
de las apariencias. Al originarse en las pasiones, el lenguaje articulado procede del amor propio, de la comparación con los otros y del olvido de uno mismo, habiéndose abandonado el amor de sí. Ahora bien, mediante el lenguaje, el amor propio puede aparentar ser más sutil y sofisticado que lo permitido por los gestos primigenios, tendiendo a ocultarse para conseguir disfrutar de la satisfacción buscada. Afirma Rousseau, a dicho efecto, que, al devenir la sociedad paulatinamente más fría, más educada, más racional, esconde un cálculo despiadado del interés. El lenguaje llega a sufrir entonces la misma mutación, tornándose menos figurado, más claro y exacto, menos irracional y poético. Habla más a la razón que al corazón, discurre por vías menos groseras, más maliciosas. En último extremo es el amor propio, la gran pasión, quien se torna más sutil, más sofisticada y tiende a ocultarse para satisfacerse más astutamente.

En conformidad con lo reiterado una y otra vez por Rousseau, al presentarse con una gran apariencia de racionalidad, el lenguaje no necesariamente abandona sus orígenes pasionales, relacionados, de forma directa, con el amor propio que impera en la sociedad. Las argumentaciones de tal pensador anticipan lo que llegarán a concluir estudios recientes sobre la implicación indiscutible de la racionalidad y los impulsos pasionales, sean éstos del signo que fuere, conforme lo ha advertido con su habitual perspicacia y rigor Robert Solomon en Not Passion's Slave y True to Our Feelings. ${ }^{11}$ Por consiguiente, no resulta superfluo insistir en la apreciación crítica de que las disquisiciones de Rousseau se abstienen de promover el

${ }^{11}$ Los estudios de Solomon sobre las pasiones no arrojan sobre ellas las connotaciones de negatividad y corrupción que abundan a lo largo de lo argumentado una y otra vez por Rousseau. Dicha diferencia tan notable en lo que al tratamiento discursivo de las pasiones se refiere proviene de la influencia mayúscula que Solomon ha recibido por parte de las propuestas desenmascaradoras e intempestivas esgrimidas por Nietzsche. 
desarrollo de una dicotomía binaria entre el dominio ejercido por las pasiones, con el apoyo de la sociedad civilizada, y la razón represora de ellas, sino que esta última las favorece deconstructoramente y hasta las enmascara en función de las apariencias, el disimulo o incluso el engańo. Expresado de forma algo diferente, el lenguaje articulado, sobre todo en lo que tiene de elocuencia desvirtuadora y retórica oportunista, sería cómplice tanto de la corrupción pasional como también de una racionalidad integrada, por necesidad lógica, en diversas instituciones sociales y civilizatorias, criticadas con insistencia por Rousseau. Tal posicionamiento argumentativo resulta incompatible con las propuestas ilustradas dirigidas a reivindicar el valor social y reformista de la racionalidad que superaría el oscurantismo anacrónico de épocas pasadas. De hecho y en conformidad con lo ya advertido, el Discurso sobre el origen y los fundamentos de la desigualdad entre los hombres mostraba cómo los individuos, partiendo de una igualdad fundamental, formaron una sociedad que les había enajenado de sí mismos. Esa sociedad alimentaba la desigualdad y la confrontación entre los ciudadanos y, con el paso del tiempo, había derivado hacia el despotismo. Ahora bien, Rousseau no sólo se limita a criticar implacablemente a esa sociedad, contemporánea de las tesis ilustradas, sino que en El Contrato Social ofrece una fórmula considerada como una salida para abandonar las limitaciones inherentes al estado de la naturaleza, sin acabar en el despotismo. Este objetivo pasaría por la creación de una sociedad nueva, donde las pasiones fueran reconducidas al bien común, al ser sometidas a los pertinentes dictámenes de la razón. Es cierto que lo formulado por Rousseau, en dicho escrito ensayístico, parece contradecir sus ataques previos dirigidos a criticar un orden social que, de hecho, no proviene de la naturaleza y, por tanto, se asienta en meras convenciones. Aun aceptando tales presupuestos, en apariencia contradictorios, se pudiera muy bien afirmar que Rousseau llega a inclinarse a favor de la salida 
del aislamiento originario, propio del estado de naturaleza, pero sin caer en la corrupción despótica impuesta por la sociedad, tan combatida por él, incluso a lo largo de lo especulado en El Contrato Social. Ineludiblemente se pronuncia dicho pensador a favor de una agregación en el que los diversos fueros individuales que ya existían un tanto dispersos y aislados en el estado de la naturaleza, se sumen en uno, sin olvidar que el amor de sí conducirá siempre a conservar la libertad e integridad individuales. De acuerdo con lo advertido en el Emilio, se precisa hallar, así pues, una forma de asociación que defienda y proteja, del modo que fuere, al individuo concreto y a los bienes de todos los asociados, por virtud de la cual, cada uno, uniéndose a los demás, no obedecería sino a sí mismo y quedaría tan libre como se hallaba en el estado de la naturaleza. Consecuentemente, los individuos se entregarían a la colectividad íntegramente, poniéndose a las órdenes de la voluntad general. Al comportarse así, dejan de ver, en los otros, meros individuos, para contemplarlos como parte del mismo ser. Significativamente en $\mathrm{El}$ Contrato social y, con más claridad, en el Discurso sobre la economía política, se evoca la metáfora de la sociedad como cuerpo vivo que utiliza Hobbes en el Leviathan. Ésta, en efecto, se erige en un ser colectivo con una moral y una personalidad propias, un nuevo sujeto que sustituye con todas las consecuencias los individuos aislados anteriores al pacto.

La voluntad general, a la que se refiere Rousseau en El Contrato Social, caracterizadora del agregado colectivo por él propuesto, constituye una significativa réplica del amor de sí, a favor del orden primigenio de la naturaleza. De manera análoga a este amor, que perseguía la conservación del individuo, la sociedad buscará también su propia conservación y la de sus componentes, siendo la voluntad general la que siempre se pronunciará a favor de promover algún tipo de genuina comunicación, conjuntamente con el bienestar de cada parte individual, sin olvidar que los hombres, en 
el estado de la naturaleza, eran iguales en su simplicidad y que, por otro lado, la sociedad había creado una nefasta desigualdad entre ellos. El contrato social, defendido por Rousseau, instauraría entre todos los miembros del agregado colectivo una cierta igualdad moral, por medio del derecho y hasta de las convenciones libremente aceptadas. Por consiguiente, lo esgrimido en El Contrato Social, no sin caer en contradicciones, deconstructoras de su propio discurso raciocinante, se presta a ser considerado como una respuesta a las circunstancia fácticas en que se hallan los individuos, como efecto, del antagonismo social, explicado por el propio Rousseau en el Discurso sobre el origen y los fundamentos de la desigualdad entre los hombres. Si la sociedad se constituía sobre el abandono del amor de sí, promovido por el amor propio, el contrato social recupera ese amor de sí y, mediante la propuesta de la voluntad general, lo extiende al conjunto de los miembros pertenecientes a colectivos concretos. Tal amor resultante posee como fin el bien de dichos miembros en su conjunto, de la misma manera que el amor de sí originariamente tenía como objetivo el del individuo particular. Así pues, la voluntad general es análoga al amor de sí, prevaleciente en el estado de la naturaleza y, de hecho, es dicha condición primigenia la que le otorga la debida validez sobre determinados agregados colectivos. ${ }^{12}$

A la hora de resumir brevemente lo que precede, conviene insistir en que, de acuerdo con lo esgrimido por el discurso argumentativo exteriorizado en los razonamientos de Rousseau, el paso del estado de naturaleza al estado civil produce una alteración decisiva en el ser humano. Tal cambio radical se debe al hecho de que el hombre primitivo, guiado por el amor de sí, realiza lo que éste le dicta. Ahora bien, una vez que ha entrado en sociedad, el hom-

${ }^{12}$ Según lo afirmado en El Contrato Social, distinguir la voluntad general de la suma de las voluntades particulares y, muy especialmente, de la voluntad de los gobernantes, constituye algo ineludible en cualquier colectividad sana. 
bre ya no puede atenerse a la misma regla y debe consultar los dictámenes de su razón, antes de tener en cuenta sus instintos e inclinaciones. Semejante transformación resulta fundamental para hallarse en condiciones de entender el paso del estado de naturaleza al estado civil, produciéndose, así pues, una ruptura ineludible con el instinto, al tiempo que se inaugura el dominio de la razón. Con simultaneidad a tal cambio, los hombres naturales que habían sido iguales en su genuina sencillez, comprueban que entre ellos se ha instaurado una nefasta desigualdad, origen de numerosos conflictos pasionales. El contrato social que propone Rousseau deconstruye la dicotomía binaria que oponía frontalmente el estado natural, en donde predominaba el amor de sí, a las imposiciones de la ciudad, basadas en el amor propio. Tal deconstrucción se produce como resultado de que dicho contrato, aunque llegue a superar el estado de naturaleza primitivo, conserva sus rasgos más cardinales, entre los que se encuentra el predominio del amor de sí, el cual se generaliza y extiende a todos los individuos en su conjunto. Consecuentemente, se crea la voluntad general, que, de hecho, no puede enajenarse jamás, pues en ella se incluye el amor de sí, no el amor propio, de todos. Tal voluntad general tiende, por definición, al bien común y los compromisos de ella emanados no son, en sí mismos, obligatorios, sino más bien pudieran ser considerados como recíprocos y mutuos, superándose, por consiguiente, la agresividad que se encontraba en la base no sólo de la sociedad, sino también de las disquisiciones en que se basaban las propuestas de Hobbes, rechazadas de forma explícita e inequívoca por Rousseau. Finalmente, conviene, sin embargo, tener en cuenta, que, de acuerdo con lo advertido por Carmen Iglesias en Razón, sentimiento y utopia, el estado de naturaleza, esgrimido, con insistencia reiterativa, por Rousseau, no deja de ser una hipótesis lógica, tal vez necesaria, para contrastar y poner de relieve la corrupción de un orden social basado en la desigualdad, que le resulta totalmente 
inaceptable a dicho pensador, quien no duda en trazar, como paradigma, digno de la debida consideración crítica y existencial, el tipo ideal del buen salvaje. Semejante hipótesis, por tanto, de un estado de naturaleza primario y anterior a la sociedad no pretende ser un hecho real, sino una premisa raciocinante, a partir de la cual pudiera fomentarse el contrato social, favorecido deconstructoramente por una voluntad general, predispuesta, de por sí, a superar desigualdades y antagonismos enajenadores e improcedentes.

\section{Bibliografía}

Aristóteles, 1985, Ética a Nicómaco, Madrid, Gredos. , 1981, The Politics, Londres, Penguin Books.

Arteta, Aurelio, 1997, La compasión. Apología de una virtud bajo sospecha, Barcelona, Paidós.

, 2002, La virtud en la mirada. Ensayo sobre la admiración moral, Valencia, Pre-Textos.

Black, Max, 1966, A Companion to Wittgenstein's “Tractatus”, Ithaca, Cornell University Press.

Broughton, Janet, 2002, Descartes's Method of Doubt, Princeton, Princeton University Press.

Carriero, John, 2009, Between Two Worlds. A Reading of Descartes's Meditations, Princeton, Princeton University Press.

Casás Fernández, Manuel, 1931, Voltaire Criminalista. Precursor del Humanitarismo en la Legislación Penal, Madrid, Editorial Reus.

Cerezo, María, 1998, Lenguaje y Lógica en el "Tractatus" de Wittgenstein. Critica interna y problemas de interpretación, Pamplona, Ediciones Universidad de Navarra. 
, 2005, The Possibility of Language. Internal Tensions in Wittgenstein's "Tractatus", Standford, CSLI Publications.

,2008, "El pensamiento y la triple dimensión de la figura en el Tractatus", en Para leer a Wittgenstein. Lenguaje y pensamiento, Luis Fernández Moreno (ed.), Madrid, Editorial Biblioteca Nueva, pp. 39-63.

Delaney, James, 2006, Rousseau and the Ethics of Virtue, Nueva York, Continuum Internacional Publishing Group.

Derrida, Jacques, 1971, De la gramatología, Buenos Aires, Siglo XXI.

, 1975, La diseminación, Madrid, Fundamentos.

, 1977, Posiciones, Valencia, Pre-Textos.

, 1989, La escritura y la diferencia, Barcelona, Anthropos.

Evans, J. Claude, 1991. Strategies of Deconstruction: Derrida and the Myth of the Voice, Minneapolis, University of Minnesota Press.

Ginzo, Arsenio, 1985, La Ilustración francesa. Entre Voltaire y Rousseau, Madrid, Editorial Cincel.

Glock, Hans-Johann, 1996, A Wittgenstein Dictionary, Cambridge, Blackwell Publishers Ltd.

Hegel, Georg Wilhelm Friedrich, 1952, Fenomenologia del Espiritu, México, FCE.

Hobbes, Thomas, 2001, Leviatán. La materia, forma y poder de un estado eclesiástico y_civil, Madrid, Alianza.

Hume, David, 1988, Tratado de la naturaleza humana, Madrid, Tecnos.

Iglesias, Carmen, 2006, Razón, sentimiento y utopía, Barcelona, Círculo de Lectores. 
Iriarte López, Iñaki, 2007, Una cruel antífrasis. Rousseau: Lenguaje, pasión y politica, Pamplona, Universidad Pública de Navarra.

Leibniz, Gottfried Wilhem, 1977, Nuevos ensayos sobre el entendimiento humano, Madrid, Editorial Nacional.

Medrano, Juan Manuel, 2016, El reino celestial del cambio. Nietzsche y la religión, Madrid, Editorial Biblioteca Nueva.

Montaigne, Michel de, 2007, Los ensayos, Barcelona, Acantilado.

Navarro Reyes, Jesús, 2007, Pensar sin certezas. Montaigne y el arte de conversar, Madrid, FCE.

Nietzsche, Friedrich, 1995, La genealogía de la moral, Madrid, Alianza.

Nordmann, Alfred, 2005, Wittgenstein's “Tractatus.” An Introduction, Cambridge, Cambridge University Press.

Pascal, Blaise, 1941, Pensées, Nueva York, Random House.

Pereda, Rubén, 2009, La necesidad. Génesis y alcance de la noción en el pensamiento metafísico modal de Leibniz, Pamplona, Eunsa.

Platón, 1988, República, Madrid, Gredos.

Rodis-Lewis, Geneviève, 1998, Descartes. His Life and Thought, Ithaca, Cornell University Press.

Romero Cuevas, José Manuel, 2016, ¿Con Nietzsche contra Nietzsche? Ensayos de critica filosófica inmanente, Madrid, Locus Solus Ediciones.

Rousseau, Jean-Jacques, 1962, Discurso sobre las ciencias y las artes, Buenos Aires, Aguilar.

, 1998, Discurso sobre el origen y los fundamentos de la desigualdad entre los hombres y otros escritos, Madrid, Tecnos.

, 1990, Essai sur l'origine des langues, París, Gallimard.

,2002, Emilio, o de la educación, Madrid, Alianza. 
, 1990, El Contrato Social, Madrid, Espasa Calpe.

Rudd, Anthony, 2003, Expressing the World. Skepticism, Wittgenstein, and Heidegger, Chicago, Open Court.

Sedgwick, Alexander, 1977, Jansenism in Seventeenth-Century France. Voices from the_Wilderness, Charlottesville, University Press of Virginia.

Solomon, Robert C., 2003, Not Passion's Slave. Emotions and Choice, Nueva York, Oxford University Press. ,2003, Living with Nietzsche. What the Great "Immoralist" Has to Teach Us, Nueva York, Oxford University Press.

, 2007, True to Our Feelings. What Our Emotions Are Telling $U_{s}$, Nueva York, Oxford University Press.

Thiebaut, Carlos, 1999, De la tolerancia, Madrid, Visor.

Villaverde, María, 1987, Rousseau y el pensamiento de las luces, Madrid, Tecnos.

Wittgenstein, Ludwig, 1969, Tractatus Logico-Philosophicus, Londres, Routledge \& Kegan Paul.

, 1969, Philosophical Investigations, Nueva York, The McMillan Company.

Recibido: 3 de mayo de 2016 Aceptado: 8 de noviembre de 2016 